\title{
Characteristics of Victims in Child Sexual Abuse Cases in Southern Provinces and Cities of Vietnam and Prevention Solutions
}

\author{
Le Van Thieu*
}

\section{Scientific Research Management Department, the People's Police University, Vietnam}

\begin{abstract}
The right to protection of human life, health, dignity and honor is the sacred and noble right, recognized in the Constitution and protected by the Vietnamese Criminal law. However, in the pass years, the situation of crimes of sexual assault including child sexual abuse in Southern provinces and cities which are 32 provinces and cities from Da Nang to $\mathrm{Ca}$ Mau has been complicated both in number and nature of activities. In this paper, the author intends to investigate the criminal situation, characteristics of victims in child sexual abuse cases, legal framework of prevention measures, as well as some recommendations for Vietnam.
\end{abstract}

Keywords: Characteristic, victim, child sexual abuse, prevent, Vietnam.

I. THE CRIMINAL SITUATION AND CHARACTERISTICS OF VICTIMS IN CHILD SEXUAL ABUSE CASES

From 2014 to $2018,3,795$ cases of child sexual abuse were reported in the Southern provinces and cities, of which 3,761 cases were investigated, accounting for $99.1 \%$. In those cases, 5,503 offenders were arrested and handled. On average, there are 759 cases in this area, with 1,100 criminals each year. The complexity of crime is not only reflected in the number of child sexual abuse cases but also in the offenders, victims and the nature of each case. The most complex and dangerous problem is that cases of child rape always account for a high proportion of child sexual abuse crimes. Specifically, in 3,795 cases of child sexual abuse, there were 2,160 cases of raping people under 16 years of age, accounting for $56.9 \%, 110$ cases of sexually assaulting people from full 13 to under 16 years of age, accounting for $2.9 \%, 1,303$ cases of intercourse or performing other sexual acts with people from 13 to under 16 years of age, accounting for $34.3 \%, 166$ cases of sexual harassing people under 16 years of age, accounting for $4.4 \%, 56$ cases of sex purchasing people under 16 years of age, accounting for $1.5 \% \ldots$...

The typical survey of 1,360 cases of child sexual abuse from 2014 to 2018 in Southern provinces and

*Address correspondence to this author at the Scientific Research Management Department, the People's Police University, Vietnam; Tel: (+84)2866860550; Fax: (+84)2862624849; E-mail: thieuvanle1975@gmail.com

1Synthesized from the Annual Review Report of the Criminal Police Departments of Police of Southern provinces and cities (2014-2018). cities, with 1,360 victims showed that victims in these cases have the following characteristics:

- $\quad$ About gender, ethnicity: All victims of sexual abuse in this area in recent years were female, in which, Kinh people were 1,230 people, accounting for $90.4 \%$; Khmer people were 130 people, accounting for $9.6 \%$.

- $\quad$ About age: Statistics show that victims under 13 years old were 990 people, accounting for $72.8 \%$; victims from 13 to under 16 years old were 370 people, accounting for $27.2 \%$. This means victims are mostly under 13 years old, who have not developed both physiologically and psychologically, which causes long-term damage to the victims' health, spirit and general development.

Occupation: According to statistics, the number of non-occupation victims was 1,130 , accounting for $83.1 \%$; there were 220 victims who were manual workers or doing housework, accounting for $16.2 \%$ and 10 victims who were students, accounting for $0.7 \%$. Since not working, victims often stay at home while their family members are away for work. Moreover, with idle time, the victims are easily groomed or seduced to gather for getting drunk ... These create changes for wrong acts toward sexual abuse.

- About education: There were 380 people graduated from junior school, accounting for 27.9\%; 190 people were in not graduated from junior school, accounting for $14.0 \% ; 270$ people were at primary level, accounting for $19.8 \% ; 520$ people had not completed primary school, 
accounting for $38.3 \%$. Due to low education, the victims are not fully aware of themselves and society. They are often passive, gullible, and do not know how to defend themselves, so they are easily seduced and bribed by subjects.

About family situation: Past research show a massive number of the victims of sexual abuse living in families without peace, with financial hardship and they lack care of parents (accounting for $51,5 \%$ ). Some children lived with their relatives as their parents work far away from home or because they are orphaned (accounting for 20.3\%). The percentage of children living in families with only a father or mother was $17.8 \%$. Some children had to go to work to earn their living, accounting for $5.5 \%$. Only $4.9 \%$ of child victims lived in ordinary families with both parents.

Relationship with the subjects causing the crime: There were 20 cases that victims were family related with offenders, accounting for $1.5 \%, 30$ cases that victims and subjects are relatives, accounting for $2.2 \%$; there were 210 cases that victims and subjects are in love relationship, accounting for $15.4 \%$; there were 1,090 cases that victims and subjects are in social and friend relation, accounting for $80.2 \%$. Especially, there were 10 cases that they were unacquainted, accounting for $0.7 \%$.

Although the proportion of family related cases is low, these are cases that seriously affect the well-known traditions and customs, moral values and cause negative public opinion.

Self-defense ability of victims: The research shows that the number of victims with selfdefense ability was 470 , accounting for $34.6 \%$; the number of victims who did not have or had little capacity to protect themselves (due to their weak physical condition or drunkenness) was 890 people, accounting for $65.4 \%$.

Regarding victims' fault factor: Of 1,360 cases of child sexual abuse, there were 440 cases where the victims were partly to blame (the victims were compliant in sexual relations, credulous, gullible, or alcohol drunk and unable to protect themselves), accounting for $32.35 \%$. Especially, of 690 cases of child rape, there were 120 cases where the victims were partly to blame, accounting for $17.39 \%$; in $100 \%$ of 200 cases of sexual intercourse with children, the victims were partly to blame. In 22 out of 26 cases of sexual assault of people from 13 to under 16 years of age, the victims were partly to blame, accounting for $84.6 \% .^{2}$

Generally, the victims of child sexual abuse cases in the Southern provinces and cities of Vietnam in recent years were female. They had no occupation and limited self-protection ability. These characteristics reflect the complex situation of child sex offenses in the Southern provinces and cities of Vietnam recently.

\section{LEGAL FRAMEWORK OF PREVENTION MEASURES}

Scholars hold different opinions on the definition of crime prevention. Crime prevention strategies vary quite significantly throughout the world. The traditional approach to crime prevention has been to try to identify the psychological and social causes of crime and to attempt to remedy these deficiencies by treating the individual offender and/or designing special educational, recreational and employment services for groups regarded as being at risk. The escalating crime rate suggests that this approach is not working. An alternative is situational crime prevention. It rests on two assumptions: that the criminal is a rational decision maker who only goes ahead with a crime where the benefits outweigh the costs or risks; and that the opportunity to commit a crime must be there. Situational crime prevention aims to remove the opportunity, and make the costs of a crime greater than the benefits. Situational crime prevention places more responsibility on the individual for ensuring his or her own safety than does traditional law enforcement, but to succeed, it needs the co-operation of the police, public and private organisations and members of the community.

Meanwhile, Perlgut, in the research "Crime Prevention for Australian Public Housing" mentions four types of prevention. First, corrective prevention attempts to prevent crime by ameliorating social conditions which seem to lead to crime, e.g. by reducing overcrowding, creating viable neighbourhoods, rehabilitating slums and providing community health clinics and recreation facilities. Second, punitive prevention uses police to deter crime

${ }^{2}$ Typical survey of 1,360 cases of child sexual abuse with 1,720 offenders and 1,360 victims in the Southern provinces and cities of Vietnam, from 2014-2018. 
through lawyers, the police courts, gaols and the legal system. Third, mechanical prevention emphasises hardware such as locks, doors and grilles. Last, environmental prevention manipulates building design and the relationship between buildings and their environment to reduce opportunities for crime.

Regarding Vietnamese legal framework, it is reqiured to take effective measures to prevent the crime, protecting children's development. In Vietnam, crime prevention refers to activities of functional agencies, organizations and the whole society that take measures towards eliminating the causes and conditions of crimes, proactively preventing crimes from happening or minimizing the harm caused by criminals, contributing to ensuring security, serving the development of the country. Criminal prevention activities have large contents, conducted by the whole society. These activities are implemented in the following two aspects:

Firstly, detecting, limiting and eliminating negative socio-economic phenomena which are the causes and conditions of the crime situation as well as of each specific crime need to be focused on. This is one of the most basic contents, expressing the humanity and the common desire of the whole society. At the same time, it is also the optimal solution to save the State budget and the efforts of the people to fight against the crime. This content originated from the perspective that punishment is neither the purpose nor the solution of crime prevention. In order to effectively prevent crimes, the causes and conditions of the offenses must first be detected. Therefore, focusing on detecting factors that are the causes and conditions of the increase of crimes should be identified as one aspect of the crime prevention activities.

Secondly, crimes need to be promptly detected to prevent and minimize its consequences and harm. On the basis of measures prescribed for organizations protecting subjects likely to be infringed upon, functional forces detect and prevent crimes from occurring. In this respect, prevention is meant to have a direct impact on limiting the increase of crime. And now that the actual capacity of the whole society is not able to eliminate all the causes and conditions of the crime, it immediately affects the crime situation in the direction of reducing the level of danger to society.

There is a dialectic relationship between the two contents of crime prevention activities mentioned above. The former has the most positive impact on the underlying cause, and at the same time creates favorable conditions to eliminate the factors that give rise to crimes in society; on the other hand, it creates a new factor for the progressive development of the country. The later has the effect on protecting the potential victims and deterring and immediately limiting the increase of the crimes. At the same time, it helps administer the society, educate and renovate those who are likely to commit crimes, creating conditions for them to improve and become useful citizens of society. Doing well on both contents can facilitate effective crime prevention.

Since the People's Police force is prescribed as a force to protect and preserve social order and safety, the force is a functional, core force and the main subject in conducting preventive activities mentioned in the later, and also participating in prevention activities in the former. It means that the People's Police force take measures as prescribed by law to protect the potential abusive subjects, detect and prevent crimes from happening, and participate in preventing the negative impact of social factors which are the causes and conditions that give rise to crimes.

\section{RECOMMENDATIONS FOR PREVENTION}

Based on the fact of case development and characteristics of victims of child sexual abuse cases in the Southern provinces of Vietnam and awareness of crime prevention, in order to improve the efficiency of crime prevention in the future, the People's Police force of the Southern provinces and cities should take the following measures:

- $\quad$ Firstly, the victim's ability to protect themselves should be enhanced through propagandizing criminal activity tactics and sex education for students.

The surveys and analyzes of child sexual offenses in Southern provinces and cities shows that the victims in these cases are still young, their cognitive ability to protect themselves is limited, so they are easy to be attacked or seduced to have sex. Therefore, the propagation of criminal activities is one of the effective solutions to actively prevent child sexual abuse crime. So, the People's Police forces need to do the following acts:

$+\quad$ Counsel the Board of Directors of Police in the Southern provinces and cities to propose functional units to consider reporting the 
operation tricks of child sexual abuse criminals on media channels. The TV station should also regularly report the trial of those who commit child sexual abuse to educate and deter those who intend to commit crimes. People need to be propagandized to understand which characteristics of victims are usually be taken advantage of to commit criminal acts. Since then, they have the direction and proactive measures to prevent crimes.

Cooperate with the Women's Union, the Committee for Mothers and Children's welfare and benefits to organize meetings to inform about these activities of the offenders so that everybody can understand and actively prevent. In addition, these meetings should include sex education content so that women, especially the ones with children under 16 years old, could take proactive measures to prevent child sexual offenses. Propaganda content should deeply analyze the tactics of taking advantage of victims' factors to commit criminal acts.

Propagandize and mobilize schools to combine lectures and sex education as well as legal knowledge about sexual offenses to let students know and comply with the provisions of law.

Cooperate with social organizations, regularly visit and remind families with young children about managing their children well and teaching them to have a proper awareness of emotional relationships and legal consciousness to avoid getting into crime.

+ Cooperate with Youth Union and People's Committee in organizing healthy cultural nights for young people to advise them the harmful effects of early love so that they have a better view of love and sexuality, contributing to limiting sexual abuse, especially intercourse with children.

Secondly, the People's Police force should strengthen the management of information on the internet as well as managing boarding-house and hotels to limit the factors of victims' fault to prevent child sexual offenses.

One of the reasons that negatively impacted the situation of child sexual abuse crime is the influence of inappropriate thought, culture, cohabiting lifestyle, making a part of teenagers have not properly perceived the values of life, the value of love and family. According to the survey, most cases of intercourse with children related to the victims' fault factor which is overpermissiveness in sexuality. This and current common accommodation and hotel services make the situation of sexual offenses against children worse. Thus, the People's Police forces need to do the following acts in order to solve the problem:

$+\quad$ Cooperate with the network security forces in managing websites, to prevent information that is inconsistent with Vietnamese traditions, especially, porn websites should be blocked while providing more educational information about traditional values of the Vietnamese people in order to honor and orient young people to preserve and promote those traditional values. In addition, the information on the internet should be more about the harmful effects of pragmatism, the negative effects of hurry, cohabiting lifestyles so that parents are more proactive in managing their children's learning, activities and relations to avoid those.

+ Cooperate with The Police force for administrative management on social order in checking conditional business lines including accommodation services. The force should ask the landlords, hotel managers to cooperate in fighting against child sexual abuse. When there are doubts about child sexual abuse activities happening at the business place such as: renting a room for a young or drunken woman or the one showing signs of disagreement to take measures to stop promptly or report to the authorities, the Regional Police immediately to quickly prevent criminal acts.

- Thirdly, The Police force should focus on improving the quality of conducting primary investigation to grasp the situation of localities, routes and areas where sexual offenders are able to commit criminal acts.

Victims of sexual offenses are mostly young people whose ability to protect themselves are limited. Many of them live in families with unfavorable circumstances. Therefore, they are easy to be coaxed to go to motels, hotels or attacked in dark, secluded places and be abused. So, the Police force in the Southern provinces and cities need to actively conduct primary investigation to grasp the situation to determine the localities, routes and areas that can be the potential 
places of crime to regularly patrol, control, arrange security forces. When conducting this, the Force need to pay attention to the followings ${ }^{3}$ :

$+\quad$ Identify key areas, localities and routes where child sexual crimes may occur, then the primary investigation here need to be conducted by functional units at commune, ward, town level.

$+\quad$ Make lists, categorize objects by particular criteria focusing on the objects with criminal records of sexual abuse, objects from other places coming to work as hired workers with suspicious expressions, children at high risk of being sexual abused.

Summarize sex offense cases committed in the area, the number of offenders; the number of victims and analyze characteristics of criminals, causes and conditions leading to criminal acts...

List criminal statistics of the types of sex offenders, namely child rape, sexual assault with children, sexual harassment with children.

On the basis of the results of the primary investigation, it is necessary to find out the rules of activities of child sexual abuse crimes to take initiative in applying effective prevention and fighting measures. At the same time, it also discovered shortcomings in activities of preventing crimes to promptly overcome.

- Fourthly, the People's Police force in this area need to advise and propose to the Provincial Party Committee, People's Council and People's Committee to support disadvantaged and sexually abused children.

Currently, there are still many difficulties in the local towns and cities in the South such as parents, family members do not have much time, conditions for care and protection of children, creating opportunities for sexual abuse occurs. Therefore, local authorities need to continue to promote and pay more attention to social support policies through vocational activities, job creation, capital support, organizing many care activities for poor households, limiting and eliminating uneducated children step by step. Provincial People's Committees coordinate with agencies and organizations to gather community's support to help

${ }^{3}$ Report on implementation of Project IV - National Crime Prevention Program of the Police of An Giang province, period 2014-2018. ensure life for helpless children building a model of boarding schools for children in remote areas, children at primary education and ones in areas where child sexual offenses are at high rate. In addition, the Provincial People's Committee should direct the Youth Union to coordinate with schools, provide members and youths to volunteer to establish free child care groups, especially primary school age children during summer vacations and organize many fun and healthy activities for children at the same time ${ }^{4}$.

Functional departments and agencies need to coordinate, have policies to timely support and treat psychological and health injuries for children who have been sexually abused and create opportunities for them to recover and reintegrate community. These organizations should build and develop friendly services for children, such as free counseling, consultation, and treatment for sexually abused children, protect and encourage children who are victims and families with children abused to denounce the crime. They should also coordinate with social organizations to help orphans and homeless children at risk of abuse with specific policies on nurturing and education, such as making them a safe life in community centers, free home places, scholarship or learning tools support for disadvantaged children, especially girls aged 12-16 years old, supporting vocational training, creating jobs for those have stopped their education, and for girls who have been seduced to sell abroad.

Prevention of child sexually abuse is not just the responsibility of families, schools but also of the whole society. Therefore, the Provincial Party Committee and Provincial People's Committee need to have guidelines to promote coordination mechanism among agencies and social organizations in the prevention of sexual abuse crime in general and this crime against children in particular to increase efficiency in this work.

- Fifthly, the Force should propose to the Government to strengthen international cooperation in socio-economic development and prevention of child sexual offenses in the area.

The survey shows that victims of sexual abuse cases often live in incomplete families or families with financial hardship. Therefore, they are more likely to fall

${ }^{4}$ Annual working summary Report of Department of Labor - Invalids and Socia Affairs in Can Tho City. 
victim to this crime as well as children trafficking crime. So, the authorities in the area need to do the followings:

Take initiative to cooperate with international organizations such as the International Red Cross, United Nations Children's Fund to develop socioeconomy, take care of people's lives, especially in remote areas, and ethnic minority areas in order to eliminate the causes and conditions of crimes.

The Police forces in the Southern provinces and cities need to strengthen international cooperation in the prevention of child sex offenses, crimes of children trafficking, initially with police in neighboring countries such as Laos, Cambodia and with international police organizations such as the Interpol and the Aseanapol to improve this type of crime prevention efficiency.

\section{REFERENCES}

Caroline Grillot and Juan Zhang (2015), “Ambivalent Encounters: Business and the Sex Markets at the China-Vietnam Borderland", in Pál Nyíri and Danielle Tan (eds.), How Chinese Engagements are Changing Southeast Asia People, Money, Ideas, and their Effects, Seattle: Washington Press.

Kreston, Susan (2005), "Investigation and Prosecution of the Prostitution of Children.", Pp. 745-788 in Medical, Legal, \&
Social Science Aspects of Child Sexual Exploitation: A Comprehensive Review of Pornography, Prostitution, and Internet Crimes, edited by S. W. Cooper, R. J. Estes, A. P. Giardino, N. D. Kellogg, and V. I. Vieth. St. Louis, MO: GW Medical.

Lim, Lin Lean, ed. (1998), "The Sex Sector: The Economic and Social Bases of Prostitution in Southeast Asia", Geneva, Switzerland: International Labour Office

MOLISA and UNICEF Viet Nam (2011), "An Analysis of the Commercial Sexual Exploitation of Children in Selected Provinces and Cities of Viet Nam",

Nguyen Quang Nghia (2008), "Crime prevention activities of The Social Order-Related Crime Investigating Police Department in Vietnam today", PhD thesis, People's Police Academy, Vietnam.

Paula Hudson (2015), "Police and Tourism Sector Partnership to Protect Children from Sexual Exploitation Vietnam and Australia", presentation held in Ho Chi Minh City, Vietnam.

Perigut, Donald (1981), "Crime Prevention for Australian Public Housing", ACPC Forum, Vol. 4, No. 3, pp. 13-7.

Reimer, J.K. (2006), "At What Price Honour? Research into Domestic Trafficking of Vietnamese Girl Children for Sexual Exploitation from Urban Slums in Phnom Penh, Cambodia", Phnom Penh: Chab Dai Coalition.

UNODC - UN Office on Drugs and Crime, "Child Sexual Exploitation in travel and tourism: a brief analysis of domestic legal frameworks in Cambodia, Laos PDR, Thailand and Vietnam"

United Nations Viet Nam, "The UN is Seriously Concerned About the Magnitude of Child Sexual Abuse in VietNam".

Zhao, Ruohui, and Jianhong Liu. (2011), "A System's Approach to Crime Prevention: The Case of Macao", Asian Journal of Criminology 6 (2): 207-27. https://doi.org/10.1007/s11417-011-9117-8

DOI: https://doi.org/10.6000/1929-4409.2019.08.13

() 2019 Le Van Thieu; Licensee Lifescience Global.

This is an open access article licensed under the terms of the Creative Commons Attribution Non-Commercial License (http://creativecommons.org/licenses/by-nc/3.0/) which permits unrestricted, non-commercial use, distribution and reproduction in any medium, provided the work is properly cited. 